\title{
Making the World a Better Place: Consumers’ Group Identity in the Markets with Competition and Two-sided Opportunism
}

\author{
Vesa Kanniainen
}

CESIFO WORKING PAPER NO. 5842

CATEGORY 11: INDUSTRIAL ORGANISATION

MARCH 2016

An electronic version of the paper may be downloaded

- from the SSRN website:

- from the RePEc website:

- from the CESifo website:

wWw.SSRN.com

www.RePEc.org

www.CESifo-group.org/wp 


\title{
Making the World a Better Place: Consumers' Group Identity in the Markets with Competition and Two-sided Opportunism
}

\begin{abstract}
Consumer boycotts often provide a disciplinary mechanism against firms deviating from established social norms. Such actions tend to be organized by people through reference groups with a social mission. The intensity of the group identity is, however, private information. Therefore, the membership is the subject of opportunistic free riding. Moreover, opportunism reinforces opportunism in the market transactions as both a deviating and a non-deviating firm can also take the advantage. Despite such limitations on the maintenance of the code of the high ethical conduct, the paper shows that the joint impact competition and the group effect support the profits of firms with a high ethical code. Paradoxically, a strong group identity effect among the consumers may advance the low ethical code as high-cost competitors are not survived. As the monitoring by the consumer groups is focused on large firms these are - against the received wisdom - more likely to adopt the code of the high ethical conduct than the small firms. Paretoefficient bargaining with the buyers' alliance may not turn out to be an attractive strategy for a firm.
\end{abstract}

JEL-Codes: D180, D430, L110.

Keywords: consumer boycotts, social identity, market opportunism, competition.

Vesa Kanniainen

Department of Political and Economic Studies

Arkadiankatu 7 (P.O. Box 17)

Finland - 00014 University of Helsinki

vesa.kanniainen@helsinki.fi

March 16, 2016

The author is grateful to Karmela Liebkind for valuable references on the group identity literature in social psychology. 


\section{Introduction}

Making the world a better place is not easy. However, the current paper suggests that despite the many adverse examples in the past and the recent emission test scandal of German Volkswagen and the tyre test scandal of Finnish Nokian Tyres, the large firms yet have a stronger incentive of adopting the ethical code of conduct in today's world than the small local firms. This view stands in contrast to the conventional wisdom where large multinational firms were accused - and for proper reasons - for misusing their market position without caring much of the ethical consequences of their behavior. The reason for such an optimism is based on two complementary mechanisms. First, the transmission of knowledge has globally become more effective resulting in intensified competition. Second - and for the same reason - consumers can undertake aggressive collective actions against deviating firms. ${ }^{1}$ The links of the small, say local, firms, to the rest of the society are weaker and they are consequently supposed to have a much more limited incentive to pay attention to their ethical code. The large firms in particular are the targets of the collective actions of consumers having built a group identity with a social mission. Many people want to feel of providing their contribution to making the world a better place.

The most important capital in the economy is the trust capital. As suggested by Baron (2001) and Besley and Chatal (2007), it is not the government but the private actors in the market, consumers and firms, which

\footnotetext{
${ }^{1}$ The most striking economic scandal of the current decade has provided by the German car producer, Volkwagen. Its cars being sold in America had software in diesel engines that could detect when subject to a testing, changing the performance accordingly to improve results. The engines emitted nitrogen oxide pollutants up to 40 times above what is allowed in the US. The company had failed in producing a diesel engine which would yield a low emission and yet have a limited consumption. The company's strategy was apparently based on the acceptance of risk of being caught. Consequently, it saw its stock price tumble about 30\% since the Environmental Protection Agency announced about the manipulation. As another recent scandal, the Finnish tyre manufacturer Nokian Tyres was caught in early 2016 for manipulated test results for years misleading the consumers about the quality of the product.
} 
create - or destroy - the fragile social capital. Indeed, the large public demands for imposing corporate social responsibility on firms. An opposite view was expressed by Friedman (1970) in his early influential writing. He was concerned on the survival of firms if they do not keep their focus in making profit. Shleifer (2004) argued that the erosion of corporate ethics may result from the intensified competition. The opposite view was taken by Hörner (2002) who suggested that the reputation effects helps to maintain corporate ethics. Frank (2004) found several mechanisms whereby a firm that incurs additional costs beyond what is required by the law is nonetheless able to prosper in competition with the more opportunistic rivals.

The current paper challenges the concerns of Friedman and Shleifer. It introduces a model where the adoption of the ethical code of conduct is the superior strategy provided that the firms behavior can be monitored. Firms' expectations of the group identity effect of the consumers are decisive and a strong group identity creates a Prisoners' Dilemma in competition. The option for opportunism among consumers, however, gives rise to opportunism among the competing firms trembling the prospects for the spreading of the meme of strong ethical principles. Opportunism reinforces opportunism in the market transactions. The asymmetric market power of firms associated with different monitoring possibilities of large firms and small firms blurs the picture.

In introducing the group effect into the market behavior, the current paper is built on the social psychology view of social identity. Some qualifications are introduced. The intensity of the group identity is taken to be private information. The product brought to the consumers may be a necessity for them and the consumers may have built a psyhological loyjalty towards the product of a company. The detection of deviating firms is stochastic and depends on the size of the firm. Finally, Pareto-efficient bargaining with the buyers' alliance may not turn out to be at all an attractive strategy for a firm. 
The history of economic scandals is impressive. The US Enron company - known for its high-ranked business values - was caught from cheating its investors, its workers, and the public in large fifteen years ago. The company was one of the largest and most respected among the listed US companies. ${ }^{2}$ Its fraught created substantial mistrust in the US economy. Enron was not the only one. Many other betrayers of the US capitalism (Arthur Andersen in auditing, Worldcom in telecommunication, Merck in pharmaceuticals, Time Warner in entertainment and others) were caught for a similar sabotage of the social values. Earlier examples of international business scandals include Nestle, Shell and Nike which all have long been the subject of long lasting consumer boycotts. ${ }^{3}$ Consumer boycotts actions against firms using the products of old growth forests, firm which bring to the market products of genetically modified contents, use child labor, exploit the rainforest, pollute the environment, resort to animals in cosmetic testing, to mention some examples. ${ }^{4}$

The above observations suggests that there is a market for morality and that the moral principles can be priced in the market place. There is a substantial literature in the area of consumer boycotts in consumer and marketing research, cf. Friedman (1999), Koku (2011). In the economic literature, in Baron (2001), the activist and the firm may bargain to settle the boycott and the boycotts are unlikely to arise in equilibrium as the target firms rationally agree. In Baron (2002) the duration of boycotts is affected by the

\footnotetext{
${ }^{2}$ For details, cf. Healy and Palepu (2003).

${ }^{3}$ Nestlé suffered from lost reputation after selling inappropriate breast milk substitute to pregnant mothers in developing countries. Shell Oil suffered damage to its image from the military action of the Nigerian government against domestic protests aimed at protecting the delta of its river. Nike was critized for abusive working conditions in overseas apparel. A smaller but an interesting case includes an Estonian company Tallink. Its ship was caught for releasing waste into the Baltic Sea in 2005. After the passengers' initiative to organize a boycott against the company and in fearing for the loss of the customers, it quickly announced a policy change, pledging to safely release waste into containers in the harbour.

${ }^{4}$ Innes (2006) reports, for example, that between 1988-1995, over 200 firms and over a thousand products were the subject of organized boycotts in the US.
} 
intransigency of the players. In Deirmeier and Van Mieghem (2005) multiple equilibria may arise as the equilibrium selected depends on the switching costs, the threshold for the success of the boycott and the importance of the social dimension of the boycott. Innes (2006) considers the boycotts as a game between a duopoly industry and environmental organisation. Delacote (undated) suggests that boycotts are often ineffective because of coordination issues, free riding and the high opportunity cost. Some earlier work has been more explicit on the motives of the consumers' boycotts (consumers' self-respect in Kanniainen and Pietarila (2006), the social punishment when abstaining from participating in Glazer, Kanniainen, Poutvaara (2010)). In Heijnen and van der Made (2012), a firm knows that consumers are concerned about its ethical standards but it does not know how much they care. The firm therefore has to update its understanding about the consumers' concerns.

However, and in terms of collective action, there may be more to it. People often want to do something important in their life. They want to live with the feeling of making a difference. They want to belong to a group with a social mission. This is indeed the regularity identified by the large research in the social psychology. A group identity theory developed by Tajfel and Turner (1979) defines a social group as people who interact with one another, share similar characteristics, and collectively have a sense of unity. The subsequent social psychological work on the group effect includes Simon (2004), Brown and Capozza (2006), and Reicher, Haslam, Spears and Reynolds (2012). The group which people belong to is an important source of pride and self-esteem. A membership is apparently based on feelings inside human beings, "conscience" - called "impartial spectator" by Adam Smith long ago. ${ }^{5}$ For motives of a boycott see also Braunsberger and Buckler (2011).

\footnotetext{
${ }^{5}$ The social and economic studies on altruism and empathy are supported by the biological research which has identified the role of oxytocine in controlling our moral feelings (Marsh et al. (2015)). The group behavior in the market place appears to provide a helpful joint research area for evolutionary studies, psychology and social sciences including
} 
The current paper asks: under what conditions are the market forces strong enough to reward the firms with a high ethical code and punish the firms which deviate? The basic architecture of the model world of the current paper is built on that of Glazer, Kanniainen and Poutvaara (2010). In that paper, a consumer arrived at a personal choice to obtain acceptance in her circle of acquaintances. The current paper examines a complementary punishment mechanism, a heteregeneous group identity. Yet, an activist has to pay a higher price if she switches from a deviating firm to a non-deviating one. She is influenced by the expectations of how many are the fellow citizens who will be committed. The profitable opportunism may make an individual give up the group identity. ${ }^{6}$ The paper identifies when the boycotts can be efficient in coordinating and reinforcing social norms and corporate responsibility. The ex ante expectations of the size of the potential boycott shape the distribution of the firms with a different ethical code as to how the customers choose the firm whose door they will open. Such ex ante effects mean that the effectiveness of the consumer boycotts may have been underestimated when based on data on realized boycotts! There is a further reason as the Pareto-efficient bargaining helps to eliminate boycott actions ex ante. Yet, there is a limit: resigning itself to the bargaining may not turn out to be an attractive strategy for a firm.

The results of the paper are many and many of them can be exposed to empirical testing. There is a unique self-fulfilling rational expectations industry equilibrium determining the distribution of the ethical code of firms. Unlike in Baron (2001), boycotts may arise in equilibrium despite symmetric economics in the spirit of Wilson consilience, see Wilson (1999). The economic behavior cannot be understood without understanding what kind of human beings we are. The human beings cannot be understood unless we understand where we come from. We know today that cooperation within established norms has been a successful strategy though the temptation of opportunism always is there.

${ }^{6}$ As the consumer actions are not registered it is not easy to have precise data on the group size. Such data would be valuable for the empirical testing of the propositions of the current paper. 
information depending on the firms' costs of the ethical code. The intensity of the group identity determines the success of the boycott. This differs from Innes (2006) who suggests that in equilibrium, boycotts are small and persistent against the small firms and large and transitory against the large firms. The paper establishes conditions for the mixed industry equilibrium with both ethical and unethical firms in the market. When there is rivalry, the ethical firm will gain from the boycott while the unethical firm will lose. This is different from Heijnen and van der Made (2012) who study an industry with a single firm.

Competition between the firms helps in imposing the ethical discipline. If the firm faces the risk of a rival firm capturing the market, the high ethical code of conduct may result from the Prisoners' Dilemma: the firms would prefer the low ethical code but in the absence of commitment with the rival, the strategy of the high ethical code becomes profit maximizing. This is against the prediction by Shleifer (2004). To maximize their profit they better adopt a socially responsible strategy even when their profits are then below what where they would be if the firms could collude on a low ethic strategy. Despite such good news, the paper suggests limits to the optimism. People can behave as free riders and give up their group identity. Anticipating such an opportunism, the firms may abstain from committing to a high ethic strategy. If the group identity effect is strong enough, only a low-cost firm may stay in the industry and as a monopolist might find it attractive to change its ethical code. Paradoxically, a strong group identity effect may undermine the firm's ethical code. Moreoever, a firm may not find a negotiation with the activist groups reasonable. This case is strong particularly when the product is a necessity. Finally, small firms cannot be monitored effectively and the deviators tend to be concentrated among them rather than among the large firms. One of the key insights of the paper is that small firms are not the subject of the group identity effect like the large ones are. Making the world a better place is thus not easy. The mankind obtains the 
world it deserves.

\section{Model}

Under what conditions do the high moral firms dominate in the industry equilibrium when adopting the ethical code is costly? In what follows, it is assumed that one of the competing firms $(A)$ is a low-cost firm and the other one $(B)$ is a high-cost firm with $k<K$ denoting their cost of adopting the ethical code. There are several potential equilibria. In a mixed equilibrium, one of the firms chooses $H$ ("high") and one of the firms chooses $L$ ("low") as their ethical codes. Another equilibrium is Prisoners' Dilemma both choosing $H$ as their pure strategy though both would prefer avoiding the cost. This results in that the code of the high ethics dominates in the market equilibrium. The question to be raised is in which way this equilibrium depends on the intensity of the group identity effect.

\subsection{Group identity among consumers}

In the model economy of the paper, there are two social groups of consumers in terms of their moral attitudes. Following Glazer, Kanniainen and Poutvaara (2010), a consumer belonging to a social group a has strict moral preferences, she is independent and not group-dependent and she never buys at a firm deviating from a social norm. Another group of consumers, say group $b$, has consumers who also want to be doing good but through some reference group. The strength of the group identity is individual-specific. The mass of consumers in group $a$ is scaled to $n$. In group $b$, it is scaled to be 1. Each consumer buys at most one unit of the product. The consumers are indexed in decreasing order, $x_{i}$ on $[0,1]$ with respect to their basic willingness to pay for the product. The consumers $x_{i}=n$ and $x_{j}=1$ have zero willingness to pay. If the highest willingness to pay, say $\beta$ in both groups is high, the product is a necessity for many consumers. The willingness to pay 
by the remaining consumers is uniformly distributed on $(0, \beta)$ in both groups. The moral concerns aside, the indirect utility functions of the consumers, say $x_{k}$ and $x_{l}$ in the two groups, are $u_{k}=\beta\left(1-x_{k} / n\right)-p$ and $u_{l}=\beta\left(1-x_{l}\right)-p$ where $p$ is the market price.

To introduce the moral concerns for the consumers in group $b$, it is assumed that each of them has an individual-specific intensity of the social identity, $\left\{\alpha_{i} \geq 0\right\}$ stating their moral attitude against a deviation from a social norm and their willingness to joint a product boycott. It is private knowledge. The total willingness to pay by each individual, call it the effective willingness to pay, has to be adjusted for this effect. For an individual, say $x_{l}$, in the group $b$, the revised willingness to pay is given by

$$
U_{l}=\beta\left(1-x_{l}\right)+\alpha_{l} X
$$

where $X=$ the size of the boycotting group of the $b$-types. Some of the customers in group $b$ may have such a low group valuation that they may opportunistically give up their membership. There is no particular reason as to why the basic willingness to pay and the intensity of the group identity should correlate. ${ }^{7}$ This makes the market demand functions in equation (1) adjusted for the group identity effect "lumpy" and non-linear. It is therefore appropriate to reorganize the customers in group $b$ according to their revised willingness to pay, $U_{l}$, to obtain monotone downward sloping demand schedules. By construction, they are non-linear and not necessarily differentiable.

In the model, the competing firms produce identical products but can choose different corporate ethics, differentiating their image among the consumers. There are four stages in the model. In stage 0 , the group identity for each consumer is determined by the "nature". The firms form their expectations of the size of the consumer alliance protesting against them if

\footnotetext{
${ }^{7}$ In the current analysis, it is not necessary to make any particular assumption of the relation between the group identity effect and the degree of necessity of the product. Yet, if anything, the correlation may be negative.
} 
they choose the low ethical code $L$. In stage 1 , the firms choose their ethical code. The paper takes non-pollusion as an example of such an ethical code. ${ }^{8}$ In stage 2, the consumers monitor the firms' type and the deviating firm is captured either with certainty (Section 2) or imperfectly (Section 3). There is a consumer with a zero cost of organizing a boycott, other consumers may join. The consumers are relocated among firms. In stage 2 of Section 2, the firms adjust their output in the light of the consumers' location and the equilibrium is obtained. In Section 3, the firms cannot adjust the output which is determined by their capacity. They therefore resort to the price competition. When the firms have a different size, the large firm does not need to pay attention to the pricing of the small firm which has a much smaller capacity.

\subsection{When opportunism reinforces opportunism}

It is first shown in this section that under differences in the cost of the ethical code of conduct, the competition can genarate a mixed industry structure. The suggestion thus is that the markets indeed are able to reward the $H$ - firm with a higher market share and greater profit than the $L$-firm has access to. It is then shown that the competition between the firms may result in a stronger form of ethical conduct, i.e. a Prisoners' Dilemma making both firms choose the high ethics as their code of conduct even if both would prefer colluding on the $L$-strategy. It is the group effect which, in particular, operates in facilitating such an industry equilibria. The intuition then suggests that the expectations of the firms concerning the intensity of the group identity of their customers are ex ante important for the choice of the ethical code.

The number of moral consumers who buy at the firm $H$ is assumed to be $x_{h}<n$. From the definition of the marginal moral consumer, the $H$-firm knows that the equilibrium price at firm $H$ has to be consistent with the willingness to pay by the marginal moral customer, $\beta\left(1-x_{h}-x_{l}\right)=p_{H}$. The

\footnotetext{
${ }^{8}$ This should be read as resorting to the accepted emission levels.
} 
model identifies those $b$-type consumers who opportunistically switch to firm $B$ thus giving up their group identity. Their number is denoted by $x_{l}$. The number of those consumers in group $b$ who - for the group identity reasons stay as the customers of the firm $H$ is denoted by $x_{m}$. The total size of the boycotting group is denoted by $X$,

$$
X=x_{h}+x_{m}
$$

The marginal such a buyer (with an index $x_{m}+x_{l}$ ) is indifferent between buying at firm $L$ or not buying the product. Her net utility is $\beta\left(1-x_{m}-\right.$ $\left.x_{l}\right)=p_{L}$. After reorganizing the $b$-type customers in monotonically declining revised willingness to pay, the marginal customer in this group, say $x_{m}$, associated with her group identity intensity $\alpha_{m}$, is indifferent at which firm to buy,

$$
U_{m}=\beta\left(1-x_{m}\right)+\alpha_{m} X-p_{H}=\beta\left(1-x_{m}\right)-p_{L} .
$$

For all the non-marginal customers, say $x_{v}$, with greater effective willingness to pay, it holds

$$
U_{v}=\beta\left(1-x_{v}\right)+\alpha_{v} X-p_{H} \geq \beta\left(1-x_{v}\right)-p_{L} .
$$

Therefore, the price premium in favor of the ethical firm, $p_{H}-p_{L}=\alpha_{m} X$, arises in the market from the product of the size of the social group of those who boycott and the intensity of the social identity of the marginal boycotting customer. $^{9}$

It is a necessary condition for the group effect to be relevant that $\alpha_{m}>0$.

\footnotetext{
${ }^{9}$ After reorganizing the consumers of type $b$, the group identity intensity is indeed monotone in that $\alpha_{v} \geq \alpha_{m}$ for all $x_{v}$. It has been argued by Zheng (2015) that the original GKP, Glazer-Kanniainen-Poutvaara model has multiple equilibria because the social punishment $b$ in that analysis is constant across individuals. However, the output distribution within the industry is unique. To have a non-uniqueness among the $b$-buyers can be obtained by introducing an individual specific $b_{i}$-intensity along the lines suggested by the current paper.
} 
For all non-marginal consumers it holds $p_{H}-p_{L} \leq \alpha_{l} X .{ }^{10}$ To solve for the number of $b$-customers with a strong group identity, $x_{m}$, eliminate the prices to obtain

$$
\beta\left(1-x_{h} / n\right)-\beta\left(1-x_{m}-x_{l}\right)=\alpha_{m} X .
$$

As the intensity of the group identity effect, however, is private information before the production decisions are undertaken, the firms have to form expectations $X^{e}$, of the size of the boycotting group.

In the current section, there are no constraints on choosing the output and the firms are engaged in the Cournot competition with the outputs denoted by $y_{H}$ and $y_{L}$. Then, $y_{H}=x_{h}+x_{m}, y_{L}=x_{l}$. As the number of moral buyers is $x_{h}=y_{H}-x_{m}$, the number of $b$ - buyers who are expected to buy at firm $H$, is solved as

$$
x_{m}=\left(\frac{n}{1+n}\right)\left[\frac{y_{H}}{n}-y_{L}+\left(\frac{\alpha_{m}}{\beta}\right) X^{e}\right] .
$$

If one of the firms is of type $H$ and the other ine is $L$, the gross expected profit of the $H$-firm is

$$
\begin{gathered}
\pi_{H}=y_{H} p_{H} \\
=y_{H} \beta\left[1-\left(\frac{1}{1+n}\right)\left(y_{H}+y_{L}-\left(\frac{\alpha_{m}}{\beta}\right) X^{e}\right)\right] .
\end{gathered}
$$

The expected profit of the $L$-firm is

$$
\begin{gathered}
\pi_{L}=y_{L} p_{L} \\
=y_{L} \beta\left[1-\left(\frac{1}{1+n}\right)\left(y_{H}+y_{L}+n\left(\frac{\alpha_{m}}{\beta}\right) X^{e}\right)\right]
\end{gathered}
$$

Thus, the expectations of the size of the potential boycott and the strength

\footnotetext{
${ }^{10}$ The expression for the price premium can be made a subject of empirical testing. Notice that the consumer surplus for the marginal consumer is zero while all non-marginal consumers enjoy a positive surplus.
} 
of the group identity of the marginal customer shape the distribution of the market shares which will be materialized when the customers choose the firm whose door they will open. Such ex ante effects forcefully support the view that the effectiveness of the consumer boycotts may have been underestimated when based on data on realized boycotts! If firms anticipate that the opportunism among the $b$-customers is expected and cannot result in a large boycott, they have free hands in choosing their ethical code. The opportunism reinforces the opportunism! On the other hand, if the firms anticipate that the opportunism among the $b$ - customers will be wide-spread, they have the access to another opportunistic option i.e. of charging a high price on the boycotting customers. ${ }^{11}$ Again the opportunism reinforces opportunism! Recall the expression for the price premium $p_{H}-p_{L}=\alpha_{m} X$.

We show first

Proposition 1. In an industry equilibrium characterized by self-fulfilling rational expectations concerning the size of the potential consumer alliance against the firm should it choose a low ethical code, and with both types of firms in the market, the low-cost firm has both a greater output and larget profit than the high-cost firm.

Proof. To have a mixed equilibrium with both types of firms active the market, it is expected that the profit and cost structure must satisfy for the low-cost firm $A$, and for a high cost firm $B$, respectively,

$$
\pi_{H}-k \geq \pi_{L}, \pi_{L} \geq \pi_{H}-K
$$

This will now be established. To produce the industry equilibrium, solve first the outputs under fixed expectations,

$$
y_{H}=\left(\frac{1+n}{3}\right)+\mu_{H} X^{e}, \quad y_{L}=\left(\frac{1+n}{3}\right)-\mu_{L} X^{e} .
$$

\footnotetext{
${ }^{11}$ Take an example from another context. When a snowstorm arises, why do the prices of the snow shovels go up?
} 
where the multipliers are

$$
\mu_{H}=\left(\frac{n+2}{3}\right)\left(\frac{\alpha_{m}}{\beta}\right)>0, \mu_{L}=\left(\frac{2 n+1}{3}\right)\left(\frac{\alpha_{m}}{\beta}\right)>0 .
$$

They depend on the number of moral customers, $n$, the group identity effect of the marginal moral customer $\alpha_{m}$ and on the degree of necessity of the product or the product loyalty for the consumers, $\beta$ in an intuitive manner. Therefore, the expected output of the $H$-firm is bigger than that of the $L-$ firm. As its price is also greater, its gross profit is greater, too. The effect of the expected consumer group identity will push up the market share - and gross profit - of the $H$ - firm and cut those of the $L$ - firm.

Solve next the output distribution of the industry under rational expectations. It is characterized by

$$
X^{e}=x_{h}^{e}+x_{m}^{e}=x_{b}=x_{h}+x_{m}=y_{H} .
$$

Then the gross profits are re-written as follows

$$
\begin{aligned}
& \pi_{H}=y_{H} \beta\left[1-\left(\frac{1}{1+n}\right)\left(\left(1-\frac{\alpha_{m}}{\beta}\right) y_{H}+y_{L}\right)\right] \\
& \pi_{L}=y_{L} \beta\left[1-\left(\frac{1}{1+n}\right)\left(\left(1+n \frac{\alpha_{m}}{\beta}\right) y_{H}+y_{L}\right)\right]
\end{aligned}
$$

with the best response reaction functions

$$
\begin{gathered}
y_{H}=\left(\frac{1}{2}\right)\left(\frac{\beta}{\beta-\alpha_{m}}\right)\left((1+n)-y_{L}\right) \\
y_{L}=\left(\frac{1}{2}\right)\left((1+n)-\left(1+n\left(\frac{\alpha_{m}}{\beta}\right)\right) y_{H}\right) .
\end{gathered}
$$


The Nash-Cournot output distribution is unique and written as

$$
\begin{aligned}
& y_{H}=(1+n)\left(\frac{\beta}{3 \beta-\alpha_{m}(4+n)}\right) \\
& y_{L}=(1+n)\left(\frac{\beta-\alpha_{m}(2+n)}{3 \beta-\alpha_{m}(4+n)}\right) .
\end{aligned}
$$

Two conditions are needed for the above output distribution for qualifying as an equilibrium and having both firms active in the market:

$$
\beta-\alpha_{m}(2+n)>0, \quad 3 \beta-\alpha_{m}(4+n)>0
$$

When the conditions (7) are satisfied, it also holds

$$
y_{H}-y_{L}=(1+n)\left(\frac{\alpha_{m}(2+n)}{3 \beta-\alpha_{m}(4+n)}\right)>0 .
$$

The output distribution above serves as the equilibrium with self-fulfilling expectations. Consumers vote by their money. Notice that in oder to have a finite output for the $H$-firm, one needs to introduce $\beta>\alpha_{m}(4+n) / 3$, a condition for the degree of necessity of the product. A large group identity effect resulting in a large group identity index of the marginal buyer at the $H$-firm supports the output of the $H$-firm. For the $L$ - firm to be active, both conditions in (7) need to hold. In particular, if $\beta<\alpha_{m}(2+n)$, the $L$ - firm will not survive in the market.

Corollary 1. If the product is a necessity, both firms can be active despite their different ethical codes. A low code of the ethical conduct is not eliminated by the market forces.

Which of the firms chooses the $H$ - code? It must be the low-cost firm $A$. Suppose that the profit of the low-cost firm would be less than that of the 
high ethic high-cost firm. This would violate the idea of an equilibrium. It must have a higher profit, i.e. the net profits satisfy

$$
\begin{gathered}
\pi_{H}^{A}=\pi_{H}-k>\pi_{L}^{A} \\
\pi_{H}^{B}=\pi_{H}-K<\pi_{L}^{B} .
\end{gathered}
$$

From the above condition (8) and the price premium in the market it follows that

Corollary 2. When the product is a necessity for many consumers, the $L$ firm benefits at the expense of the H-firm, yet remains a smaller one.

\subsection{When the high moral dominates in the market: Pris- oners' Dilemma}

The above case of mixed equilibrium apparently is the dominating one in the real world. However, a particularly interesting case arises if the demand and cost structure satisfies

$$
\begin{gathered}
\pi_{H}^{A}-k \leq \pi_{L}^{A} \\
\pi_{H}^{B}-K \leq \pi_{L}^{B} \\
\pi_{H}^{A}-k \geq \pi_{L}^{B} \\
\pi_{H}^{B}-K \geq \pi_{L}^{A} .
\end{gathered}
$$

This is the case of the Prisoners' Dilemma: though both firms suffer from profit losses when choosing $H$ the best they can do is both to adopt $H$ strategy though they would prefer colluding at the $L$-strategy. The group 
identity effect reinforces the case of the Prisoners' Dilemma: ${ }^{12}$

Proposition 2. A group identity among the consumers increases the plausibility of the Prisoners' Dilemma.

Proof. An intuitive proof is sufficient. If the firms agree on a price cartel, they could both choose the $L$ - strategy. In the absence of credibility, however, both would have the incentive to deviate choosing $H$. The $L$-firm would suffer substantially. According to the results above (Proposition 1), the gain of the $H$ - firm is positively related to the group identity effect $X$ and so is the reduction in the profits of the $L$ - firm. The conditions for the Prisoners' Dilemma to arise and to have both firms active in the market equilibrium, there must be conditions, particularly upper limits to he costs of the ethical code, $k, K$. If both these costs were very low, neither firm would choose the $L$-strategy as it would lose all moral customers. If these costs were very high, neither firm would choose the $H$ - strategy as it would be unprofitable. There must be a non-empty intermediate range satisfying the conditions for the Prisoners' Dilemma (9).

Notice that if the switch of customers between the firm arising from the group identity effect were very strong the high cost firm $B$ would make a loss and would exit. This would create a monopoly position for the $H$-firm which would have an incentive to switch from an $H$-firm into an $L$-firm. One obtains a paradoxical result:

Corollary 3. If the group identity effect in a consumer boycott is very strong, it may results in reduction in the quality of the ethical code in the market.

Whether a monopolist firm follows the $H$-strategy or switches to the $L-$ strategy depends on the detection probability. This issue will be studied in the next section.

\footnotetext{
${ }^{12}$ The previous work (Kanniainen and Pietarila (2006), Glazer, Kanniainen, Poutvaara (2010) has established the conditions for the existence of the Prisoners' dilemma in a related analysis.
} 


\section{Small firms and large firms: stochastic rev- elation}

The analysis in the previous section abstracted from the consumers' imperfect ability to monitor the firms. Instead, perfect monitoring and cost-free observability of the ethical code of the firms was assumed. Moreover, the model studied focused on competing firms with no capacity constraint in adjusting their output. In the real word, firms have a different size. They arise from differentiated market success or differential managerial ability in the past. The consumers, the activists in particular, but today also a larger audience are more able to monitor large firms than the small ones. The global communication techniques have been developed through the internet and the transmission of information has become highly efficient. The world is today watching more carefully than in the past especially the activities of the large multinational firms which have often been accused for unethical strategies and of misusing their economic power. Less resources are allocated to monitor small local firms with much fewer customers and, say, also fewer workers. In this section, both the assumption of perfect monitoring and of homogeneity of firms are relaxed. The activists specialize in monitoring large firms in particular. ${ }^{13}$ Therefore, differentiated detecting probabilities are introduced, say $p>q$, for the large and for the small firms. In modelling the size difference when the firms produce identical products, capacity constraints are introduced.

To highlight the role of the size difference between the firms, it is assumed that the small firm indeed is very small when compared with the large one. This means that though the firms compete in the market place for the customers by their image, the small firm is unable to have an impact on the strategy of the large firm. Though the firms have a fixed capacity they still

\footnotetext{
${ }^{13}$ This can be motivated by that their externality created can be much more harmful than that of the small firms. In Innes (2006), the gain of the Environmental Organizatrions from monitoring large firms is greater than on monitoring small firms
} 
can optimize how much to sell leaving potentially some output unsold at zero cost.

Two questions are raised. First, which of the firms is likely to choose the high ethical code instead of the low one? Second, what difference does it make whether the consumers have a strong group identity instead of a weak one? As the large deviating firm is revealed with a greater probability it is the large firm which apparently has a greater incentive of adopting the high ethical code of conduct more often than a small firm. The implication is somewhat surprising: the consumer boycott might lead to evolution of the market structure in favor of large firms in particular as the group identity represents in a great risk for a deviating firm as it may result in a large boycott. Indeed, there is asymmetry: the small firms are more seldom "victims" of the group identity effect.

After the monitoring of the firms' ethical code by their customers, the market game may have four different structures. First, the consumers may have the understanding that both firms have adopted the ethical code. This case arises from several possibilities. It is possible that both firms indeed have chosen the ethical code. It is also possible that only one of them has chosen, or that neither has chosen but that the consumers just did not catch the deviators. This case is thus analyzed as if both firms were ethical. Second, it is possible that either the small or the large one has deviated and is revealed. Finally, it is possible that both firms have deviated and both are revealed.

Suppose first and if only for the sake of illustration that both firms are ethical and of equal size but cannot adjust their output. The mutual competition is in this case of the Bertrand type and the equilibrium price would be zero regardless of whether there are more or less buyers than products produced and available for the consumers. The standard undercutting argument applies. The ethical firm would for sure run a deficit as it has committed to the costly cleaning of the emission. Thus, it would have a strong incentive to avoid this cost and adopt the unethical code in the first place. Imperfect 
observability might make this choice attractive.

Let the firms now be of a different size. The large one can consider itself to be in a position of a monopolist - the small one cannot capture its market whatever it does. However, the large one loses all the moral customers of group $a$ if it is chooses the $L$ - strategy and is captured. The consumers of type $b$ would prefer to switch the firm but the capacity of the small firm is too small to sell to all of them. The expected profit of the large $L-$ firm is given by

$$
E\left[\pi_{L}^{L}\right]=(1-p) \pi_{H}^{L}+p \pi_{L}^{L},
$$

where the super index $L$ refers to the size of the firm and the sub indices $H$ and $L$ to its ethical code perceived by its customers like in Section 2 .

Suppose that the unrevealed large firm prices its product as $p_{M}$. It obtains $x_{A}$ moral customers of type $a$ where $x_{A}$ is solved from

$$
\beta\left(1-x_{A} / n\right)=p_{M}
$$

The number of $a$-type customers is thus

$$
x_{A}=n\left(1-p_{M} / \beta\right)
$$

As it is unrevealed, it also obtains $x_{B}$ customers of type $b$ where $x_{B}$ is obtained from ${ }^{14}$

$$
\beta\left(1-x_{B}\right)=p_{M}
$$

Their amount is

$$
x_{B}=1-p_{M} / \beta .
$$

The profit of the unrevealed large firm of type $L$ is then

$$
\pi_{H}^{L}=(1+n)\left(1-p_{M} / \beta\right) p_{M},
$$

\footnotetext{
${ }^{14}$ No group effect is involved as the large firm is not revealed from cheating.
} 
and its profit-maximizing price is

$$
p_{M}=\beta / 2 \text {. }
$$

Then, the sales and the realized profit are

$$
x_{A}+x_{B}=n / 2+1 / 2, \pi_{H}^{L}=\frac{(1+n)}{4} \beta .
$$

These conclusions hold given that it has sufficient capacity to satisfy the demand ${ }^{15}$,

$$
x_{A}+x_{B}=\frac{1+n}{2} \leq Y .
$$

Assume now instead that the large firm which had not chosen the ethical code was captured. It loses all the moral customers, $x_{A}=0$. The customers (most of them) of type $b$ do not have the option of switching to buy at another firm. The only way to boycotting is to abstain from buying. If none of the $b$-types boycotts, and given the monopoly price, say $p_{m}$, the number of the remaining customers of the revealed large firm is solved from $\beta\left(1-x_{z}\right)=p_{m}$ and is $x_{z}=1-p_{m} / \beta$.

However, if the product is not a necessity for all customers and some of the $b$-types, say $x_{b}$, organize a boycott against the large firm with a marginal group member, say $x_{s}$, the indifference condition for the marginal participating customer is ${ }^{16}$

$$
\beta\left(1-x_{s}\right)=p_{m}+\alpha_{s} X_{b}^{*}
$$

Here $X_{b}^{*}$ denotes the non-buying consumers and thus the number of buying customers is reduced to

$$
x_{s}=1-p_{m} / \beta-\alpha_{s} X_{b}^{*} / \beta .
$$

\footnotetext{
${ }^{15}$ If the capacity is not sufficient some customers are not served.

${ }^{16}$ In order to arrive at this condition, one needs to reorganize the customers in the same way as was done in Section 2 to obtain the monotone effective willingness to pay schedule.
} 
Notice that the large firm now has two types of non-buying customers, those who regard the price too high and those who want to boycott against it. ${ }^{17}$

How is the number of boycotting customers $X_{b}^{*}$ determined? It is equal to the number of non-buying customers i.e. it coincides with $n+1-x_{s}$. Then, the indifference condition for the marginal $b$-buyer is

$$
\beta\left(1-x_{s}\right)=p_{m}+\alpha_{s}\left(n+1-x_{s}\right)
$$

and the solution for the number of buyers is

$$
x_{s}=1-\frac{p_{m}+\alpha_{s} n}{\beta-\alpha_{s}} .
$$

To summarize, the price, the sales and the profit for the large deviating firm are

$$
p_{m}=\frac{\beta}{2}-\frac{\alpha_{s}(n+1)}{2}, x_{s}=1-\frac{\beta+\alpha_{s}(n-1)}{2\left(\beta-\alpha_{s}\right)}, \pi_{L}^{L}=\frac{\left[\beta-\alpha_{s}(n+1)\right]^{2}}{4\left(\beta-\alpha_{s}\right)} .
$$

Comparing the price, sales and profits,

Lemma 1. The large firm having chosen the unethical code and captured is subject of rather substantial punishment from the moral consumers and those consumers who are subject of the group identity effect and who do not find its product a necessity. Its sales drop substantially and it accumulates an unsold inventory.

Proof. From above,

$$
p_{M}=\frac{\beta}{2}>\frac{\beta}{2}-\frac{\alpha_{s}(n+1)}{2}=p_{m}
$$

\footnotetext{
${ }^{17}$ This case differs from that in Section 2 where the buyers had to choose between two firms with a different ethical code. Here, all $a$-types are boycotting the large firm and some $b$-types join particularly those who do not regard the product as a necessity. A $b$-type who does not join the boycott will not be able to have personal pleasure from the group identity effect.
} 


$$
\begin{gathered}
x_{A}+x_{B}=\frac{n+1}{2}>1-\frac{\beta+\alpha_{s}(n-1)}{2\left(\beta-\alpha_{s}\right)}=x_{s} \\
\pi_{H}^{L}>\pi_{L}^{L} .
\end{gathered}
$$

Even the large firm is, however, captured probabilistically. If it is of type $H$, it obtains the (gross) profit $\pi_{H}^{L}$ with probability 1 but it obtains an even higher profit if is of type $L$ (with probability $1-p$ ) but not caught as it avoids the cost of cleaning. Comparing the cases of unrevealed and revealed large firm, it pays for the large firm to choose the ethical code if $(1+n) \beta / 4-k>(1-p)(1+n) \beta / 4+p\left[\beta-\alpha_{s}(n+1)\right]^{2} / 4\left(\beta-\alpha_{s}\right)$ or if the catching probability is high enough,

$$
p>\underline{p}=\frac{4 k\left(\beta-\alpha_{s}\right)}{(1+n) \beta-\left[\beta-\alpha_{s}(n+1)\right]^{2}} .
$$

Though this expression is quite involved, one can see the following regularities:

Lemma 2. The larger the number of a-type moral customers, $n$, is the smaller is the catching probability which justifies the choice of the ethical code. On the other hand, a firm tolerates a high catching probability if the cost of cleaning, $k$, is large.

The small firm is in a rather different situation. When choosing its ethical code, it takes the strategy of the large firm as given. It knows that the large one is either of type $H$ or type $L$ but that in the latter case it is caught only probabilistically. However, it is only the price charged by the large firm which matters for the small firm. The small firm maximizes its profit subject to the constraint that its price cannot exceed the price of the large firm. It cannot attract many customers of the large firm as its capacity is small.

To formalize, assume that the large firm has chosen its price $p_{M}=\beta / 2$. 
The expected profit of a small firm then is

$$
E\left[\pi_{L}^{S}\right]=(1-q) \pi_{H}^{S}+q \pi_{L}^{S}
$$

where $q<p$. An ethical or unrevealed small firm prices its product as $p_{N} \leq$ $p_{M}$. An ethical small firm is able to sell its capacity output, say $Q$, at a price which is marginally below the price of the large firm. Its profit is thus

$$
\pi_{H}^{S}=p_{M} Q-k
$$

A small firm whether ethical or unethical is able to sell all of its output as long as there are sufficiently many customers who are not concerned of their group identity. The market does not price the ethics of the small firm. The profit of the unethical small firm whether captured or not thus is

$$
\pi_{L}^{S}=p_{M} Q
$$

Regardless of its catching probability, a small firm has no incentive to adopt the ethical code. A rather dramatic conclusion follows:

Proposition 3. Large firms adopt the ethical code if their catching probability is large enough. The small firms never adopt the costly ethical code.

Proof. The proof follows from $\pi_{H}^{S}<\pi_{L}^{S}$.

Therefore, in the current framework the strong prediction is that the small firms never choose the ethical code of conduct.

\section{Why not enter the Pareto-efficient bargain- ing?}

The option of bargaining between the firms and the consumer alliance is always open as suggested by Baron and Innes. Why do the partners not 
always resort to it? The current section suggests that there may be two reasons. First, the catching probability of a deviating firm, $p$, may not be that large. Second, the bargaining power of the firm may be large especially if the product is a necessity. ${ }^{18}$

Consider the case where the firm is a large one as analyzed in Section 3. Then the role of the small rival firm is irrelevant. The firm can choose whether to enter bargaining with the consumer alliance ex ante or abstain from it. The bargaining concerns the firm's ethical code and the price. When accepting the bargaining, the firm has to commit to pay the cost $k$ acknowledging that the bargaining price, say $p^{B}$ will reflect the valuation of the product by the buyers' alliance. Alternativelly, the firm can abstain from bargaining choosing $L$ as its ethical code and subjecting itself to stochastic detection. Its optimal strategy is thus determined by the criterion

$$
\max \left\{\pi^{B}, E\left[\pi_{L}\right]\right\}
$$

where $\pi^{B}$ is the profit under the bargaining,

$$
\pi^{B}=p^{B} x^{B}-k
$$

The bargaining price is determined from the problem

$$
\max _{p^{B}} \Gamma=\pi^{B}+\theta\left(\int_{0}^{x^{m}} c s_{j} d j\right)
$$

where $1>\theta \geq 0$ measures the bargaining power of the consumer alliance of size, say $x_{m}$, and $c s_{j}$ measures the net valuation of the product to the alliance member $j$ given by her consumer surplus $c s_{j}$. One may consider both the case where the firm has a flexible capacity (Section 2) or a fixed capacity (Section 3) in production. The logic is essentially the same though in the

\footnotetext{
${ }^{18}$ There is a third reason not studied in the current model: the coordination costs within the consumer alliance may not be trivial - despite the modern social media which has reduced those costs substantially when compared with the past.
} 
previous case, the firm has more flexibility and it may therefore appreciate less the option of bargaining with the consumers' alliance.

The indifference condition for the firm's participation in bargaining is

$$
\psi=\pi^{B}-E\left[\pi_{L}\right]=0
$$

Define the firm's profit function under bargaining as $\tilde{x}^{B}=\tilde{x}^{B}\left(p^{B}(p, \theta)\right)$ where $0<p<1$ is the detection probability and where $\partial \tilde{x}^{B} / \partial p=0, \partial \tilde{x}^{B} / \partial \theta<$ 0 . From the previous section one can see that $\partial E\left[\pi_{L}\right] / \partial p<0$. From above, it is clear that $\partial E\left[\pi_{L}\right] / \partial \theta=0$. Consider a firm which used to be indifferent on whether to enter the bargaining or not. Then an increase in the bargaining power of the consumer alliance makes the firm less willing to bargain as $\partial \psi / \partial \theta<0$. The effect of the catching probability $p$ goes the other way round: $\partial \psi / \partial p>0$. Therefore,

Proposition 4. An increase in the catching probability increases the firm's incentive to enter the bargaining between the consumer alliance while an increase in its bargaining power has the opposite effect

$$
\frac{\partial \psi}{\partial p}>0, \frac{\partial \psi}{\partial \theta}<0
$$

The Pareto-efficient bargaining does not always appear attractive. ${ }^{19}$

\footnotetext{
${ }^{19}$ There is a further point to be raised. Commitment into the code of a costly ethical conduct can be an irreversible project involving a sunk cost. This may make the firm adopting the $L$-strategy instead but allow for bargaining with the environmentalists if caught. In this case, a two-stage approach is needed. In the negotiation process, the group effect may also be stronger if the activists keep in memory the firm's past behavior. Moreover, the firm's willingness to negotiate may also depend negatively on the size of the fixed cost of cleaning and of the degree of necessity of its product.
} 


\section{Final remarks}

The question examined in this paper is whether a firm with the code of a costly ethical conduct can survive. According to the current analysis, the answer is yes if the group identity effect rewards the ethical code of conduct. People value not only the products they consume but the image of the producer is often equally important. Such preferences have been introduced in the current paper where people may undertake organized punishment actions against those producers who deviate from the established norm. The idea of the group identity and its role in shaping the power of consumer alliances against the firms was based on research in social psychology suggesting that people value their membership in social groups with a mission. A market mechanism based on such group formation was shown to support those values which help to maintain social norms and social capital in the society. Consumer alliances and boycotts represent such a disciplinary function of the market mechanism. Reasons were suggested in terms of opportunism among consumers why the actions of such groups may not be effective. It was, however, also suggested two reasons why they can make a difference. First, the expectations of firms concerning the power of the group identity effect will ex ante have an impact on the ethical choice of firms. Second and against the conventional vision, large firms may have a greater incentive than small firms in adopting a high ethical code. Also Volkswages and Nokian Tyres got caught. By implication, the social responsibility of large multinational firms could be extended to exporting strong corporate culture to those developing countries where they are operating. The current paper has examined a number of mechanisms not typically discussed by economic papers. Many of its results could be made the subject of empirical testing. The last point to be made, however, is a warning. It always remains unknown what the final judgement of the values expressed in the market place is. People get easily brainwashed by treacherous memes as forcefully demonstrated by Blackmore (1999). Be not blind as to the power of the market 
mechanisms! The markets may also support norms and outcomes which are socially harmful. The mankind gets the kind world that it deserves!

\section{References}

Baron, D.P., (2001), "Private Politics, Corporate Social Responsibility, and Integrated Strategy", Journal of Economics \& Management Strategy, 10:1, 7-45.

Baron, D.P., (2002), "Private Politics and Private Policy: A Theory of Boycotts", Stanford, Graduate Scjhool of Business, Research Paper N:o 1766.

Besley, T., and Ghatal, M., (2007), "Retailing Public Goods: The Economics of Corporate Social Responsibility", Journal of Public Economics 91, 1645-1663.

Blackmore, S., (1999), The Meme Machine, Oxford University Press.

Braunsberger, K., and Buckler, B., (2011), "What motivates consumers to participate in boycotts: Lessons from the ongoing Canadian seafood boycott", Journal of Business Research 64, 96-102.

Brown, R. and Capozza, D. (Eds.) (2006): Social Identities. Motivational, Emotional and Cultural Influences. Hove. Psychology Press.

Delacote, P., "Are consumer boycotts effective?", undated mimeo, http://idei.fr/sites/default/files/medias/doc/conf/ere/pap

Diermeier, D., and Van Mieghem, J., (2005), "A Stochastic Model of Consumer Boycotts", Working paper, COSM-05-001, Northwestern University. 
Frank, R.H., (2004), What Price the Moral High Ground?, Princeton University Press.

Friedman, Milton, (1970), "The social responsibility of business is to increase its profits", New York Times Magazine, 13 September.

Friedman, Monroe, (1999), Consumer Boycotts: Effecting Change Through the Marketplace and Media. Routledge.????

Glazer, A., Kanniainen, V., and Poutvaara, P., (2010), "Firms' Ethics, Consumer Boycotts, and Signalling", European Journal of Political Economy 26, 340-350.

Healy, P.M., and Palepu, K.G., (2003), "The Fall of Enron", Journal of Economic Perspectives, 17(2): 3-26.

Heijnen, P., and van der Made (2012), A., (2012), A Signalling Theory of Consumer Boycotts", Journal of Enviromental Economics and Management, 63, 404-418.

Hörner, J., (2002), "Reputations and Competition, American Economic Review, 92(3): 644-663.

Kanniainen, V., and Pietarila, E., (2006), "Corporate Social Resposibility: Can Markets Control?", Homo Oeconomicus 23(2), 153-179.

Koku, P.S., (2011), "On Boycotts Organized Though the Internet", Journal of Marketing Development and Competitiveness, 5(6), 83-93.

Kritikos, A., and Bolel, F., (2004), "Punishment as a Public Good. When Should Monopolists Care about a Consumer Boycott?", Journal of Economic Psychology 25, 355-372. 
Marsh, N., Scheele, D., Gerhard, H., Strang, S., Enax, L., Weber, B., Maier, W., and Hurlemann, R., (2015), "The Neuropeptide Ocytocin Induces a Social Altruism Bias", The Journal of Neuroscience, 25, November 2015, 35(47): 15696-15701.

Reicher, $\quad$ S. D., Haslam, S. A., Spears, R. and Reynolds, K. J. (2012). "A social mind: The context of John Turner's work and its influence". European Review of Social Psychology, 23, 344-385.

Tajfel, H., and Turner, J. C. (1979). "An Integrative Theory of Intergroup Conflict" in W. G. Austin \& S. Worchel (Eds.), The social psychology of intergroup relations (pp. 33-47). Monterey, CA: Brooks/Cole.

Sam, A., and Innes, R., (2004), "Voluntary pollution reductions and the enforcement of environmental law: an empirical study of the 33/50 program", WP, University of Arizona.

Shleifer, A., (2004), "Does Competition Destroy Ethical Behavior?", American Economic Review 94, 414-418.

Simon, B. (2004). Identity in Modern Society. A Social Psychological Perspective. Malden: Blackwell.

Heijnen, P., and van der Made, A., (2012), "A Signalling Theory of Consumer Boycotts", Journal of Envirommental Economics and Management 63, 404-418.

Wilson, W., (1999), Concilience. The Unity of Knowledge, Random House.

Zheng, Y., "Firms' Ethics, Consumer Boycotts, and Signalling: a Comment", December 17, 2015. 